Dr. med. Bernhard Heinrich
Hämatologisch-onkologische Praxis
Augsburg

Psychoonkologie

35 - Kinder krebskranker Eltern

38 - Krebspersönlichkeit

\title{
Psychoonkologie
}

\section{Leben mit Krebs erträglich machen}

- Krebs - das Wort, vor dem alle Angst haben: Patienten, die gehofft haben, dass andere Ursachen für ihre Beschwerden bestehen; der Arzt im Aufklärungsgespräch, der nicht weiß, wie sein Patient reagieren wird; Angehörige der Patienten, die scheinbar hilflos daneben stehen.

Keine andere Diagnose wird so unmittelbar mit Tod, Schmerzen und Verlust der Selbstständigkeit in Zusammenhang gebracht wie Krebs. Auch die besseren Behandlungsmöglichkeiten vieler Krebserkrankungen haben daran nichts geändert. Möglicherweise trägt die zunehmende Medienpräsenz des Themas mit Bevorzu-

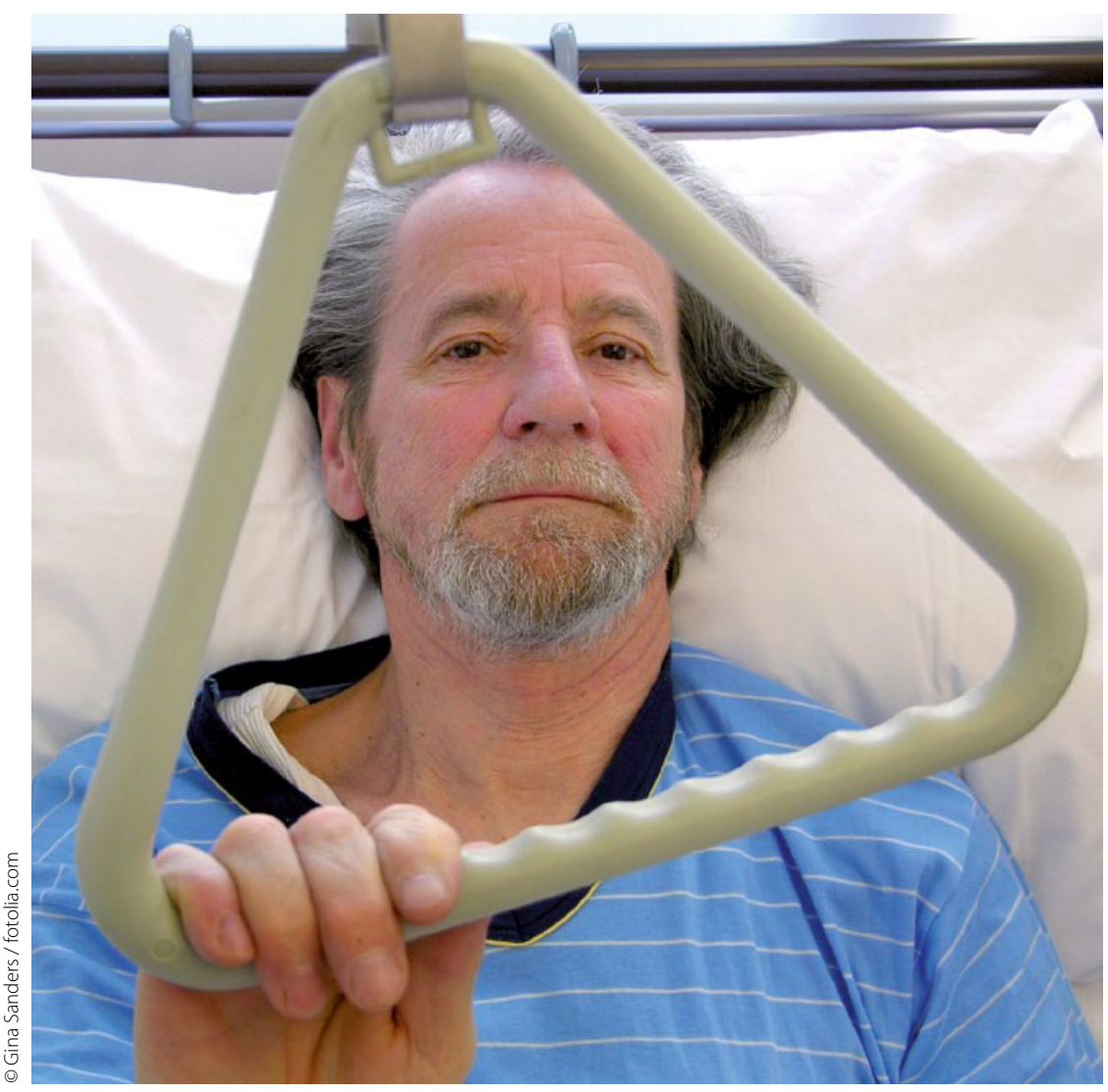

gung negativer Verläufe dazu bei. Kurzes Beispiel: Jack Nicholson im Film „Das Beste kommt zum Schluss". Der Protagonist ist an einem Prostatakarzinom erkrankt und bekommt seine erste Chemotherapie. Ergebnis: Sein gerade verzehrtes, extra extern bestelltes Menü wird sofort publikumswirksam erbrochen, als gäbe es keine Antiemetika, ganz abgesehen davon, dass die beim Prostatakarzinom durchgeführte Chemotherapie kaum emetogen ist.

Was ich damit sagen will: Krebskranke und ihre Angehörige sowie (noch) nicht Krebskranke sind kontinuierlich Informationen ausgesetzt, die die Unheilbarkeit und die Leiden bei Krebs untermauern. Die Diagnose Krebs ist deshalb selbst gegenüber anderen nicht malignen Erkrankungen mit ähnlich schlechter oder schlechterer Prognose viel stärker angstbesetzt.

Die Fragen „Warum ich?", „Wie geht es mit mir und meiner Familie weiter?" bestimmen verständlicherweise das Denken der Patienten. Ein Verständnis der dahinter liegenden Gedankengebäude sind zentrale Themen in der Psychoonkologie und wichtig für jeden onkologisch tätigen Arzt. Die folgenden Artikel sollen deshalb den aktuellen Stand der Dinge zum Thema "Krebspersönlichkeit“ und "Umgang mit Kindern von Krebspatienten" darstellen.

Mit dem Begriff der Krebspersönlichkeit sind Generationen von Patienten abgestempelt worden - immer mit dem Beigeschmack „,selbst schuld“. Im Artikel von Herrn Scholz wird Schluss gemacht mit dem Mythos, aber auch gezeigt, warum er noch weiter leben wird. Der zweite Artikel befasst sich mit den Auswirkungen der Krebserkrankung auf die Kinder der Patienten, wie Fehlentwicklungen erkannt werden und eine möglichst angstfreie Umgebung geschaffen werden kann. Ziel beider Arbeiten ist es, die Krankheit für alle erträglich zu machen. 